\title{
CBD Reverts the Mesenchymal Invasive Phenotype of Breast Cancer Cells Induced by the Inflammatory Cytokine IL-1 $\beta$
}

\author{
Lázaro García-Morales ${ }^{1}{ }^{\circledR}$, Aída M Castillo ${ }^{2}$, José Tapia Ramírez ${ }^{3}$, Horacio Zamudio-Meza ${ }^{1}$, \\ Ma del Carmen Domínguez-Robles ${ }^{1}$ and Isaura Meza ${ }^{1, *}$ \\ 1 Department of Molecular Biomedicine, Centro de Investigación y de Estudios Avanzados del Instituto \\ Politécnico Nacional. Avenida Instituto Politécnico Nacional 2508, Ciudad de México 07360, Mexico; \\ lazaro.garcia@cinvestav.mx (L.G.-M.); drhzamudio@gmail.com (H.Z.-M.); \\ mdomingu@cinvestav.mx (M.d.C.D.-R.) \\ 2 Department of Physiology, Biophysics and Neurosciences, Centro de Investigación y de Estudios Avanzados \\ del Instituto Politécnico Nacional. Avenida Instituto Politécnico Nacional 2508, Ciudad de México 07360, \\ Mexico; aidacast10@hotmail.com \\ 3 Department of Genetics and Molecular Biology, Centro de Investigación y de Estudios Avanzados del \\ Instituto Politécnico Nacional. Avenida Instituto Politécnico Nacional 2508, Ciudad de México 07360, \\ Mexico; jtapia@cinvestav.mx \\ * Correspondence: imeza@cinvestav.mx; Tel.: +52-5557473330
}

Received: 29 February 2020; Accepted: 27 March 2020; Published: 31 March 2020

\begin{abstract}
Cannabidiol (CBD) has been used to treat a variety of cancers and inflammatory conditions with controversial results. In previous work, we have shown that breast cancer MCF-7 cells, selected by their response to inflammatory IL-1 $\beta$ cytokine, acquire a malignant phenotype (6D cells) through an epithelial-mesenchymal transition (EMT). We evaluated CBD as a potential inhibitor of this transition and inducer of reversion to a non-invasive phenotype. It decreased 6D cell viability, downregulating expression of receptor CB1. The CBD blocked migration and progression of the IL- $1 \beta$-induced signaling pathway IL-1 $\beta / \mathrm{IL}-1 \mathrm{RI} / \beta$-catenin, the driver of EMT. Cannabidiol reestablished the epithelial organization lost by dispersion of the cells and re-localized E-cadherin and $\beta$-catenin at the adherens junctions. It also prevented $\beta$-catenin nuclear translocation and decreased over-expression of genes for $\Delta \mathrm{Np} 63 \alpha, \mathrm{BIRC} 3$, and ID1 proteins, induced by IL-1 $\beta$ for acquisition of malignant features. Cannabidiol inhibited the protein kinase B (AKT) activation, a crucial effector in the IL-1 $\beta / I L-1 R I / \beta$-catenin pathway, indicating that at this point there is crosstalk between IL-1 $\beta$ and CBD signaling which results in phenotype reversion. Our 6D cell system allowed step-by-step analysis of the phenotype transition and better understanding of mechanisms by which CBD blocks and reverts the effects of inflammatory IL- $1 \beta$ in the EMT.
\end{abstract}

Keywords: CBD; inflammatory IL1 $\beta$; signaling pathways; phenotype reversion; cancer treatment

\section{Introduction}

Inflammation is considered a critical component of cancer progression. The presence of inflammatory cytokines in the tumor microenvironment has been linked to an aggressive phenotype in cancer cells [1]. In particular, it has been proposed that increased levels of IL-1 $\beta$, derived from the microenvironment of malignant cells, activate inflammation that promotes invasiveness [2].

Previous work by our group has shown that binding of the inflammatory cytokine IL-1 $\beta$ to its receptor IL-1RI, present in non-invasive MCF-7 breast cancer cells, triggered the initiation of epithelial-mesenchymal transition (EMT) by activation of the signaling pathway 
IL-1 $\beta / I L-1 R / \beta$-catenin [3-5]. The transition was initiated by striking modifications of the intercellular junctions and the actin cytoskeleton of the epithelial cells. The cells detached from each other acquiring a mesenchymal morphology and increased migration and invasiveness [3]. Disorganization of cell-cell contacts led to internalization of cell junction proteins among those $\beta$-catenins which were translocated to the nucleus. The $\beta$-catenin acted as a transcriptional coactivator, modulating the expression of genes and proteins downstream of the IL-1 $\beta$-activated signaling pathway to complete the EMT and the acquisition of an aggressive phenotype of the so-called $6 \mathrm{D}$ cells. These data supported the proposal by us and other authors of a relationship between cancer development and an inflammatory microenvironment $[6,7]$.

For several years cannabidiol, CBD, a constituent of Cannabis sativa without psychotropic effects, has been empirically used as an anti-inflammatory drug and modulator of cancer progression. Recent studies highlighted that CBD is toxic at different concentrations in diverse cells, making the results obtained in cell models and the clinic difficult to interpret and, therefore, for defining the proper dose for patients [8]. On the other hand, in vitro studies have shown that activation of the cannabinoid receptors modulates different steps of tumorigenesis in several types of cancer $[9,10]$. It is known that CBD downregulates metastasis and replication in highly invasive cells by inhibiting expression of the ID-1 gene [11]. Cannabidiol has also been proposed as an inducer of apoptosis and autophagy, two mechanisms involved in decrease of cancer cell growth [12]. These reports have suggested that CBD has a potential role in the treatment of tumors and chronic inflammatory diseases. Therefore, a better understanding of the cellular and molecular mechanisms underlying CBD activities is imperative for its safe administration in patients, particularly when treatment is prolonged $[8,13]$.

Our present work was directed to explore if the anti-inflammatory activity of CBD could hinder and reverse the IL-1 $\beta$-induced EMT, leading to malignancy. We used our breast cancer invasive $6 \mathrm{D}$ cells model $[4,5]$. It was found that $6 \mathrm{D}$ cells have high levels of $\mathrm{CBD}$ receptor $\mathrm{CB} 1$. CBD bound to $\mathrm{CB} 1$ is internalized and released in the cytoplasm. At this point, inactivation of AKT by CBD results in the inhibition of $\beta$-catenin nuclear translocation and downregulation of genes and proteins identified as markers of malignancy in the activated EMT. The inactivation of AKT by CBD increased $\beta$-catenin and E-cadherin expression, and their relocation at the cell contacts to form adherens junctions and recover an epithelial phenotype.

\section{Results}

\subsection{Viability of Cells Treated with CBD is Related to Downregulation of CB1}

In vitro $\mathrm{CBD}$ anticancer activity is reported to be selective for aggressive cancer cells at concentrations that do not affect normal cell lines [12]. Understanding the mechanisms underlying its selectivity and its various activities has become a critical issue for its administration as a safe palliative or an adjuvant in cancer therapy. As a first approach to this study, the effect of CBD on cell viability was evaluated in the $6 \mathrm{D}$ model of breast cancer cells. Figure $1 \mathrm{~A}$ shows that at $10 \mu \mathrm{M}$ CBD viability of the non-invasive MCF-7 cells, used as control in all the experiments, was approximately $90 \%$ and in $6 \mathrm{D}$ cells was reduced to $69 \%$. At higher CBD concentrations the viability was rapidly reduced. At $20 \mu \mathrm{M}$ viability was only $25 \%$ in both cell lines. Therefore, $10 \mu \mathrm{M}$ CBD $\left(\mathrm{IC}_{50}=10.24 \mu \mathrm{M}\right)$ was chosen for our study, as, at this concentration, there was a statistically significant difference in viability between MCF-7 and 6D cells. Figure 1B shows data from three independent experiments using CBD and the CB1 antagonist AM251. At $100 \mathrm{nM}, \mathrm{AM} 251$ had no effect on the cell viability. When AM251 was added prior to $\mathrm{CBD}, 6 \mathrm{D}$ cells' viability did not decrease, indicating that the CBD effect occurs through interaction with the $\mathrm{CB} 1$ receptor. 

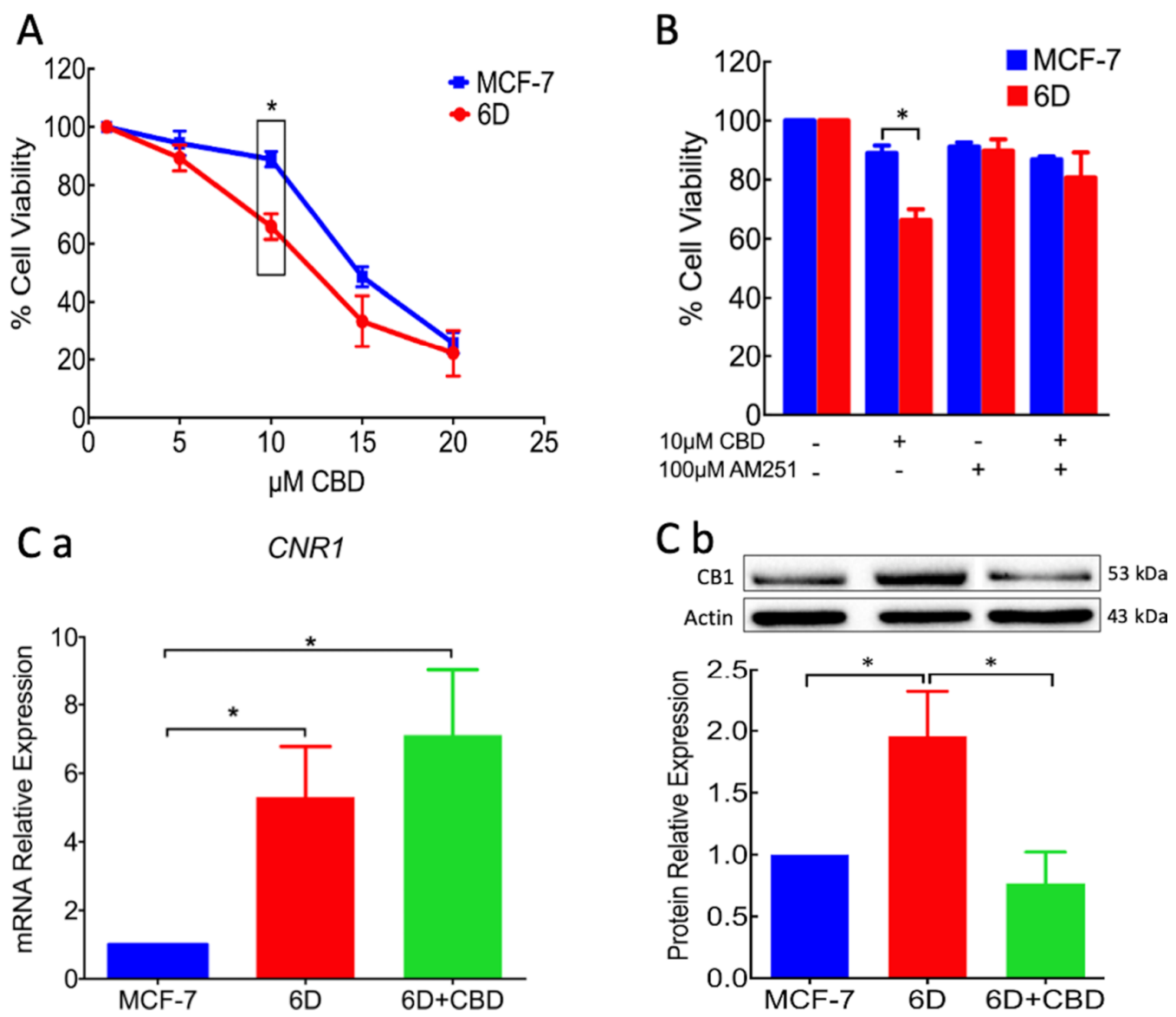

Figure 1. Cell viability and CB1 receptor expression in MCF-7 and 6D cells treated with CBD. (A) Cannabidiol concentration-response curve by cells after $48 \mathrm{~h}$ treatment. At $10 \mu \mathrm{M} \mathrm{CBD}$, the viability difference between the two cell types was statistically significant (Box). (B) Cell viability of MCF-7 and 6D cells treated in three different experimental conditions: (1) cells without any treatment, (2) cells treated with $10 \mu \mathrm{M} \mathrm{CBD}$, (3) cells treated with $100 \mathrm{nM}$ AM251 and (4) cells treated with AM251 and then with CBD. The MCF7 and 6D cells without any treatment were given $100 \%$ viability values in these experiments, data represent three independent batches of cells (biological replicates) were each examined in triplicate (assay replication, $n=9$ ). (Ca) CNR1 gene expression determined by qRT-PCR in MCF-7 and 6D cells treated or not treated with CBD. $(\mathbf{C b})$ A representative Western blot of CB1 protein in the three types of cells and the densitometric analysis of CB1 levels. The values were normalized to actin as the protein load control and expressed relative to those in MCF-7 cells. The mRNA expression and Western blot results represent the average of three independent experiments $\pm \operatorname{SD}(n=3)$. Asterisks indicate significance at $p<0.05$.

Considering that the difference in viability of the MCF-7 and 6D cells could be related with different expression of CB1, qRT-PCR was performed to investigate the expression of the gene CNR1 that encodes this receptor. Figure 1Ca shows low expression of CNR1 in the MCF-7 cells, a close to 5 fold higher expression in 6D cells but a non-significant increase in 6D cells treated with CBD. These data showed that in 6D cells, CNR1 was overexpressed in respect to MCF-7 cells. Therefore, CBD did not regulate $C N R 1$ transcription. Figure $1 \mathrm{Cb}$ shows a representative Western blot and the densitometric quantification of CB1 levels in three different cell extracts from MCF-7 and 6D cells. The receptor levels in 6D cells was 2 fold higher than those in MCF-7 cells, while CB1 in 6D cells treated with CBD, decreased below the levels in MCF-7 cells.

These results suggested that CBD downregulates CB1 receptor levels. Therefore, we hypothesized that $6 \mathrm{D}$ cells after CBD treatment should be expected to be less aggressive cells. 


\subsection{CBD Decreases Cell Migration and Resistance to Cisplatin in 6D Cells}

To test the above expectation, the effect of CBD on aggressive features such as migration and resistance to cisplatin was analyzed. In $6 \mathrm{D}$ cells treated with $10 \mu \mathrm{M}$ CBD migration was measured by a wound closure assay. Representative phase contrast microscope images, taken from three independent assays, showed the migration of the cells through a $500 \mu \mathrm{m}$ wounded area (limited by discontinuous lines) at $0,24,48$, and $72 \mathrm{~h}$ in each experimental condition (Figure 2A). The images show that cell migration in $6 \mathrm{D}$ cells treated with CBD was slower than in $6 \mathrm{D}$ cells. Quantification of the percentage of wound closure over time is shown in Figure 2B. At 48 h, 6D cells covered 91.7\% of the wound area and CBD-treated $6 \mathrm{D}$ cells only covered $42.2 \%$. At $72 \mathrm{~h}$, the wound area was $100 \%$ closed by $6 \mathrm{D}$ cells, while CBD-treated cells only covered $47.5 \%$ of the wounded area. At this time, the wound closure of CBD-treated $6 \mathrm{D}$ cells in respect to those observed at $48 \mathrm{~h}$ was only $5.3 \%$, showing that CBD treatment significantly delayed the migration of $6 \mathrm{D}$ cells.
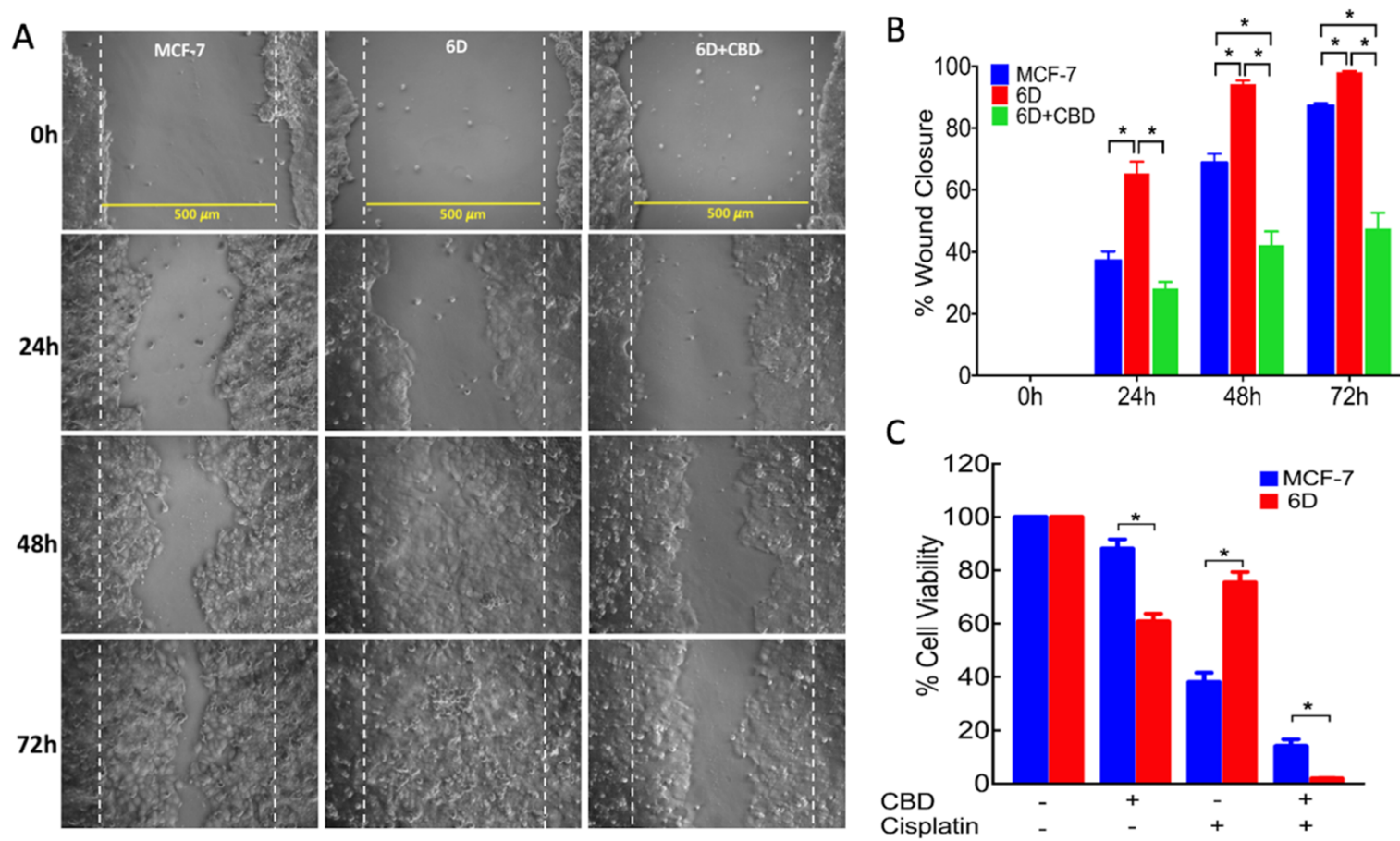

Figure 2. Cell migration and cell viability assays. The MCF-7 and 6D cells were cultured to $90 \%$ confluence and wounded to obtain a clear area of $500 \mu \mathrm{m}$ flanked by dotted parallel lines. After making the wound, a set of $6 \mathrm{D}$ cells was treated with $10 \mu \mathrm{M}$ CBD. (A) Closure of the wound was registered every $24 \mathrm{~h}$ by phase contrast microscopy until $72 \mathrm{~h}$. (B) The percentage of wound closure was measured in all the experimental conditions by image analysis and represent the average of three independent batches of cells (biological replicates) were each examined in quadruplicate (assay replication, $n=12$ ). (C) Resistance to $100 \mu \mathrm{M}$ cisplatin was evaluated by cell viability assays. Data from three independent experiments are presented as percentage of viable 6D cells relative to control MCF-7 cells $(n=9)$. Asterisks indicate significance at $p<0.05$.

Resistance of the cells to the anticancer drug cisplatin was determined as another aggressive feature. Figure $2 \mathrm{C}$ shows that $6 \mathrm{D}$ cells after $\mathrm{CBD}$ treatment had $60.5 \%$ viability and in the presence of cisplatin showed $75 \%$ viability, while cells previously treated with CBD and then with cisplatin showed $1.8 \%$ viability. The lower viability of $6 \mathrm{D}$ cells treated with $\mathrm{CBD}$ and cisplatin is consistent with $\mathrm{CBD}$ enhancing the sensitivity of the cells to the drug. The MCF-7 cells as a non-invasive cancerous type showed $88 \%$ viability in the presence of CBD and only $38 \%$ when treated with cisplatin. Unexpectedly, if these cells were pretreated with CBD, their viability in the presence of cisplatin decreased to $24 \%$. This indicated that the combination of the two drugs increased the sensibility of the cells. These 
results together with those above, showed that the two features of malignancy present in $6 \mathrm{D}$ cells were reduced by CBD treatment.

\subsection{CBD Induces Adherens Junction Formation in $6 D$ Cells}

During the search for the molecular mechanisms by which CBD could be causing a decrease of cell migration and resistance to cisplatin in 6D cells, we analyzed the morphology of the cell-cell contacts disrupted in $6 \mathrm{D}$ cells by IL-1 $\beta$ [3]. Figure 3 shows the immunofluorescence images of MCF-7, $6 \mathrm{D}$, and CBD-treated $6 \mathrm{D}$ cell monolayers stained with specific antibodies to E-cadherin and $\beta$-catenin, two proteins that are the main components of the adherens junctions [14,15]. E-cadherin is also a marker of an epithelial phenotype, while $\beta$-catenin, besides its structural role in the membrane, when internalized and transported to the nucleus regulates expression of several genes involved in the EMT progression [4,5]. Figure 3A,B show that a confluent MCF-7 cell monolayer has clearly defined adherens junctions in the cell periphery, containing E-cadherin and $\beta$-catenin. In contrast, Figure 3C,D show that $6 \mathrm{D}$ cells are detached from each other and have acquired a mesenchymal phenotype. E-cadherin is localized in the cytoplasm and $\beta$-catenin is translocated into the nuclei. A residual fraction of the proteins remains in the disorganized cellular junctions. When $6 \mathrm{D}$ cells were treated with CBD (Figure 3E,F), E-cadherin was observed in the adherens junctions of a reconstituted monolayer. $\beta$-catenin is no longer localized in the nuclei but is accumulated in thickened cell contacts. These results showed that CBD treatment promotes the relocalization of the E-cadherin $/ \beta$-catenin complex to reestablish an epithelial phenotype.

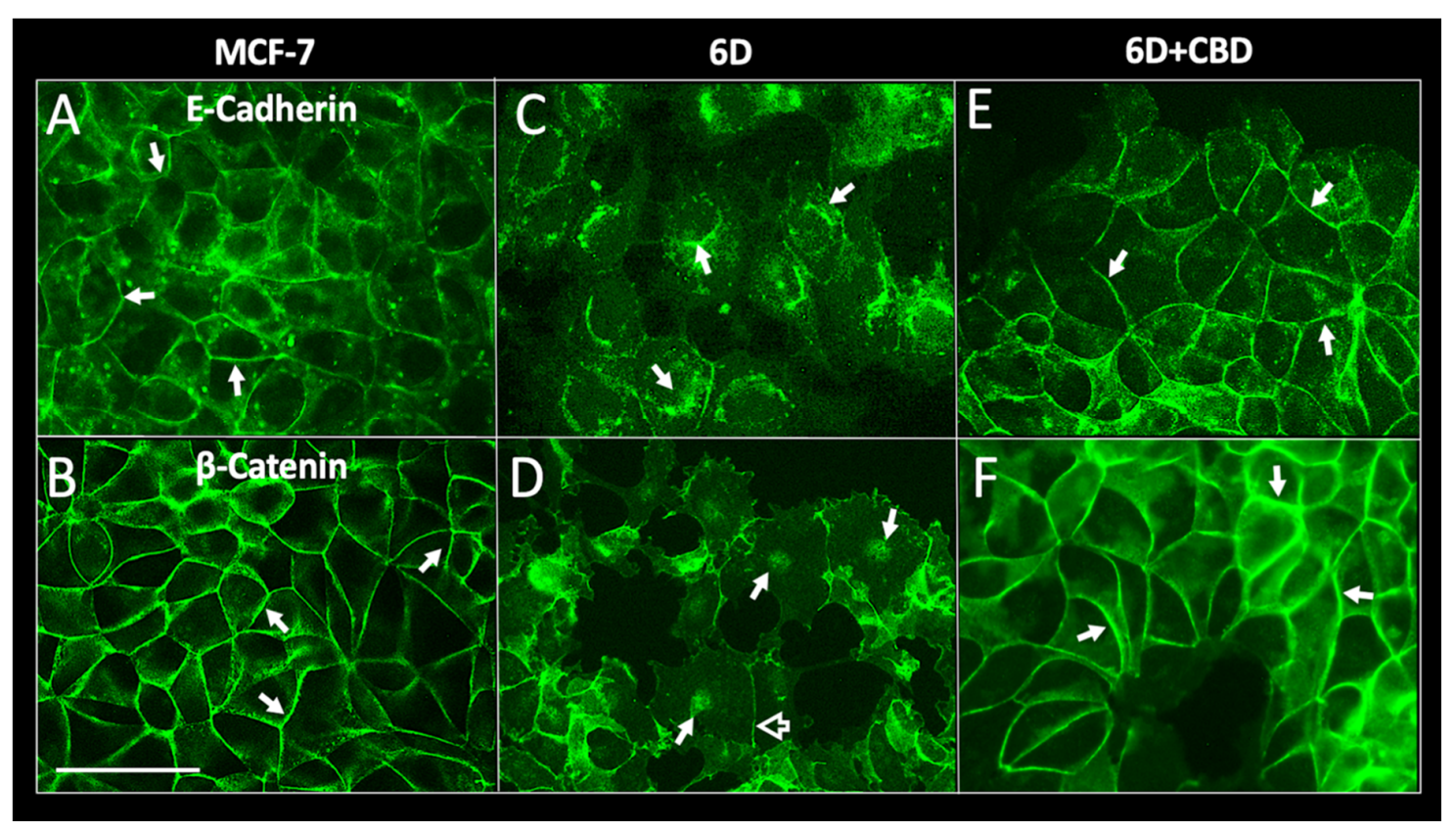

Figure 3. Immunolocalization of adherens junction proteins E-cadherin and $\beta$-catenin. MCF-7 and 6D cells treated or not treated with $10 \mu \mathrm{M}$ CBD were cultured for $48 \mathrm{~h}$, fixed, and stained with specific antibodies to E-cadherin and $\beta$-catenin. (A) E-cadherin is localized in the periphery of MCF-7 cells. Adherens junctions are indicated by arrows. (B) $\beta$-catenin in MCF-7 cells also is localized at the intercellular junctions (arrows). (C) In 6D cells stained to visualize E-cadherin the protein is in the cytoplasm and around the nuclei (arrows). (D) $\beta$-catenin in the dispersed 6D cells is localized in the nuclei (arrows) and a faint signal is still visible in the remaining junctions (empty arrow). (E) 6D cells treated with $10 \mu \mathrm{M}$ CBD showed E-cadherin normal localization in the periphery of the cells making contact (arrows). (F) In 6D cells treated with CBD, $\beta$-catenin is localized and mostly increased in the reconstituted adherens junctions (arrows). In addition, $\beta$-catenin is no longer detected in the nuclei. Bar $=50 \mu \mathrm{m}$. 


\subsection{Quantification of $\beta$-catenin in the Cell Junctions and the Nuclei in $6 D$ Cells Treated with CBD}

$\beta$-catenin in $6 \mathrm{D}$ cells treated and not treated with CBD were quantified at the cell contacts and in the nuclei. Figure $4 \mathrm{~A}$ shows representative images of $\beta$-catenin-stained cells. A density fluorescence profile across the cell membrane of cells was performed and quantified in 150 cells in six random fields. The integrated values of all the measurements are displayed in the graph on the right. The values showed that $\beta$-catenin in the cell contacts of CBD-treated cells increased 2 fold compared to the $\beta$-catenin in $6 \mathrm{D}$ cells. The lower levels of this protein in the $6 \mathrm{D}$ cells could be explained as this protein is known to be degraded when it remains in the cytoplasm.

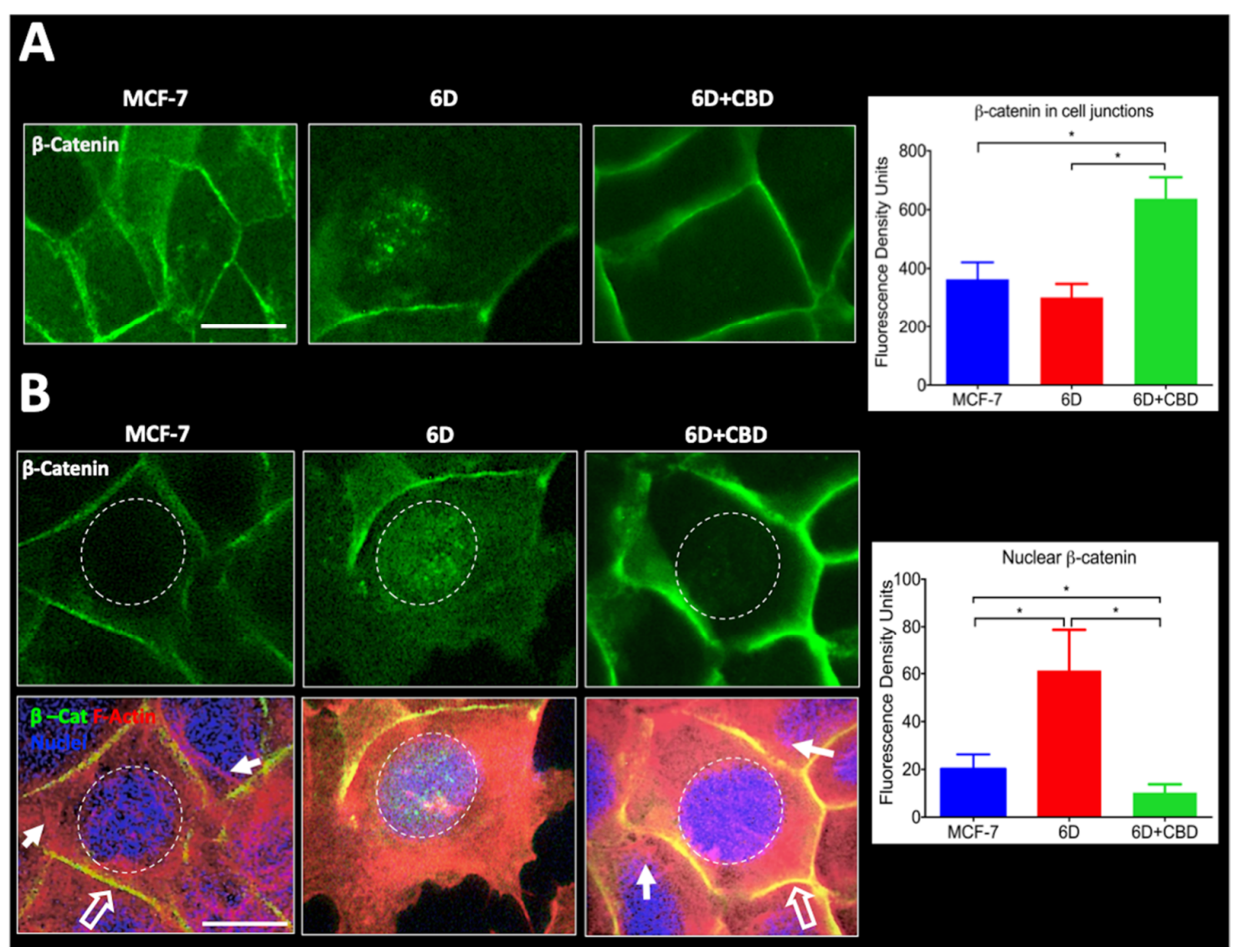

Figure 4. Quantification of $\beta$-catenin levels in cell junctions and nuclei. (A) The three panels in the figure show representative images taken from randomly selected fields to measure the fluorescence density levels of $\beta$-catenin in the cell junctions of MCF-7 and 6D cells treated or not treated with CBD. The graph on the right shows the fluorescence density units obtained. (B) Top panels show images of MCF-7 and 6D cells treated or not treated with CBD and stained with anti- $\beta$-catenin antibody to visualize and measure the protein in the nuclei. The graph on the right shows the fluorescence density values obtained. The bottom panels show cells stained with phalloidin to visualize actin fibers (red), nuclei (blue) and $\beta$-catenin (green). The graph on the bottom shows the obtained values of nuclear $\beta$-catenin levels. Fluorescence density units results represent the average of three independent batches of cells (biological replicates, $n=3$ ) \pm SD. Full arrows indicate actin fibers, empty arrows indicate colocalization of actin and $\beta$-catenin in the cell junctions (yellow). Asterisks indicate significance at $p<0.05$. Bar $=20 \mu \mathrm{m}$.

In Figure 4B, the top panels show that $\beta$-catenin was mainly found in the nuclei of $6 \mathrm{D}$ cells, although in some cells it was still associated with the remains of the disorganized cell contacts. After CBD treatment, $\beta$-catenin was relocated to the cell junctions and was no longer found in the nucleus. To quantify nuclear $\beta$-catenin, the blue-fluorescent DNA stain DAPI was utilized (Figure $4 B$, lower 
panels). Data from an intensity fluorescence profile obtained from 150 cells in six different fields are shown in the graph to the right which indicates that nuclear $\beta$-catenin levels were 3 fold higher in 6D cells than in MCF-7 and greatly decreased in CBD-treated 6D cells. Phalloidin counterstain was used to visualize the distribution of actin filaments, as they have an important role in preserving the epithelial cell morphology and polarity. The 6D cells treated with CBD showed the peripheral ring of actin co-localizing with the $\beta$-catenin at the adherens junctions and stress fibers in the cytoplasm. These structures are not present in the $6 \mathrm{D}$ cells where actin was diffused in the cytoplasm and into the migratory formed structures.

\subsection{CBD Upregulated $\beta$-catenin and E-cadherin $m R N A$ s and Protein Levels}

As the nuclear translocation of $\beta$-catenin is a key factor in the IL-1 $\beta$-induced EMT, regulation of genes and proteins that participate in the transition were analyzed in the presence or absence of CBD. Quantitative RT-PCR of genes CTNNB1 and CDH1 that encode $\beta$-catenin and E-cadherin, respectively, showed that in $6 \mathrm{D}$ cells treated with $\mathrm{CBD}$, the transcription of the two genes was upregulated in comparison with the transcription in 6D and in control MCF-7 cells (Figure 5Aa,Ba). Western blots showed that $\beta$-catenin levels were raised in the cell extracts of $6 \mathrm{D}$ cells in comparison with levels in the MCF-7 and even more in cells treated with CBD (Figure 5Ab). Figure 5Bb shows that E-cadherin only increased when 6D cells were treated with CBD. Densitometric analysis from three independent cell extracts showed low content of $\beta$-catenin in MCF-7 cells, in $6 \mathrm{D}$ cells $\beta$-catenin was overexpressed 0.5 fold and in $6 \mathrm{D}$ cells treated with CBD, expression increased 2 fold. E-cadherin in $6 \mathrm{D}$ cells was below the baseline levels in control cells but was increased 0.5 fold in cells treated with CBD (Figure 5Ab,Bb). These results showed that CBD upregulates the gene expression and protein levels of structural components of adherens junctions. The increased levels of E-cadherin and $\beta$-catenin by CBD and their accumulation in the intercellular junctions will permit the recovering of an epithelial architecture.

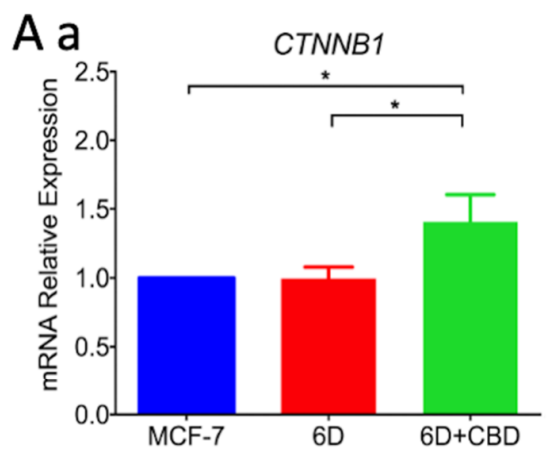

$A b$
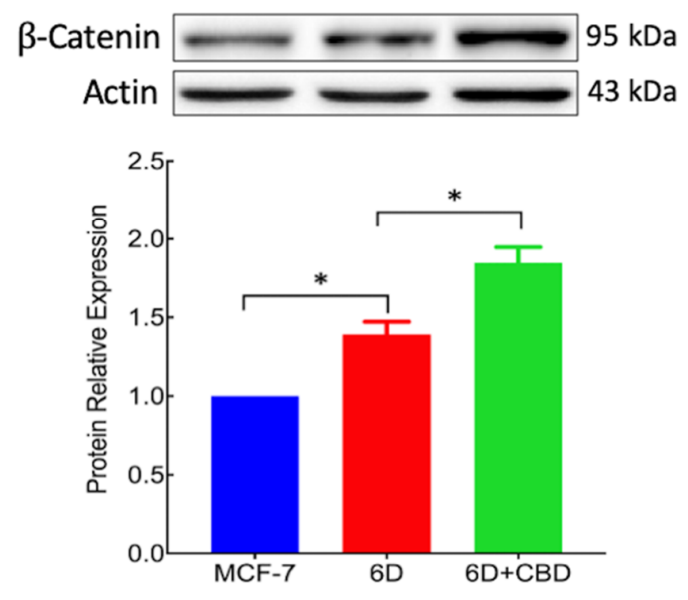
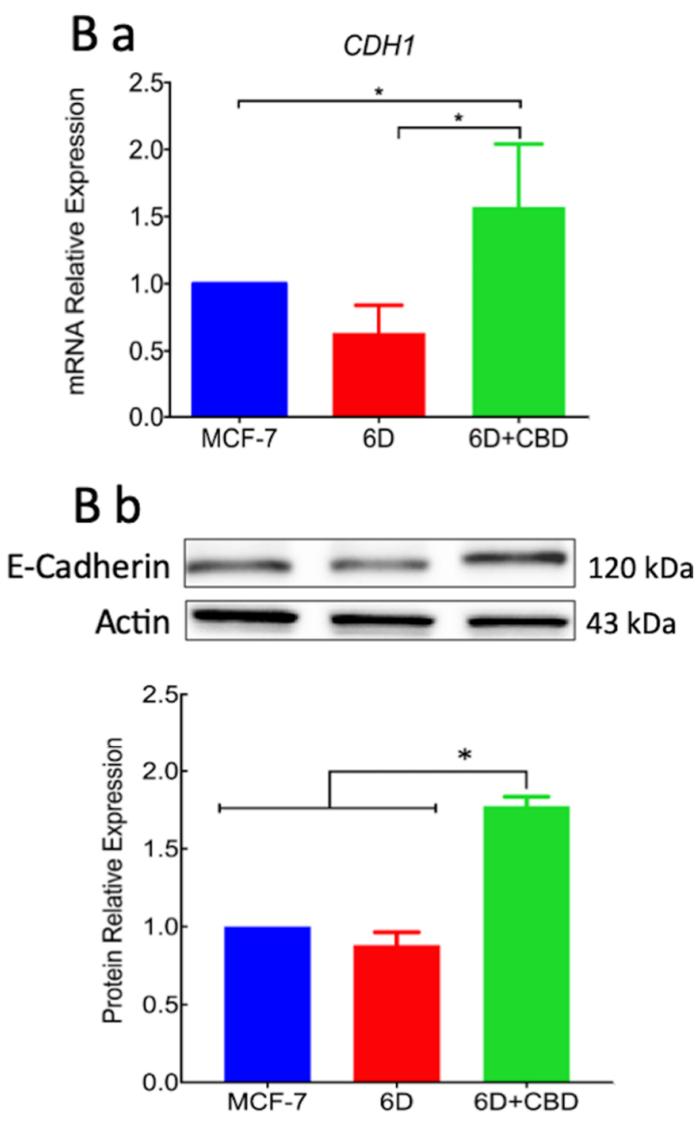

Figure 5. The CBD increased the levels of adherens junction proteins. (Aa) Expression of the CTNNB1 
gene that codifies for $\beta$-catenin was determined in MCF-7, 6D, and CBD-treated 6D cells by qRT-PCR and values obtained normalized to the expression levels of the gene RPLPO. (Ab) Western blot of $\beta$-catenin in the three types of cells mentioned above. (Ba) mRNA relative expression levels of the gene CDH1 that codifies for E-cadherin in cells not treated and treated with CBD. (Bb) Representative Western blot of E-cadherin levels in the three types of cells and densitometric values of E-cadherin levels. Values were normalized to actin and expressed relative to those obtained in MCF7 cells. mRNA expression and Western blot results represent the average of three independent batches of cells (biological replicates, $n=3) \pm$ SD. Asterisks indicate $p<0.05$.

\subsection{CBD Decreased the Expression of Proteins Related to the IL-1 $\beta$ Signaling Pathway}

As the above data revealed that addition of CBD to 6D cells caused morphological and molecular changes described in the IL-1 $\beta$-induced EMT, we investigated if CBD could have a negative effect on the expression of genes and proteins that participate in this process [16,17]. Therefore, qRT-PCR analysis was performed for BIRC3, TP63, and ID1 genes. Figure 6Aa shows that BIRC3, which was already overexpressed 5 fold in 6D cells, decreased to less than 1 fold when cells were treated with CBD. The TP63 expression also increased in 6D cells (3 fold) and decreased to MCF-7 mRNA levels when treated with CBD (Figure 6Ba).

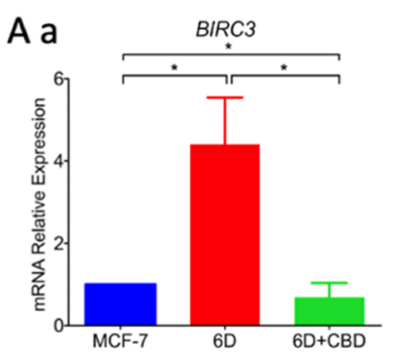

$\mathrm{Ab}$
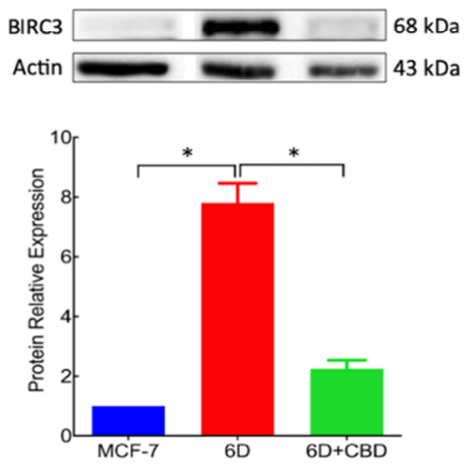

B a

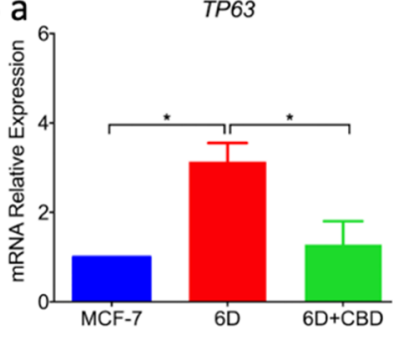

$\mathrm{B}$ b
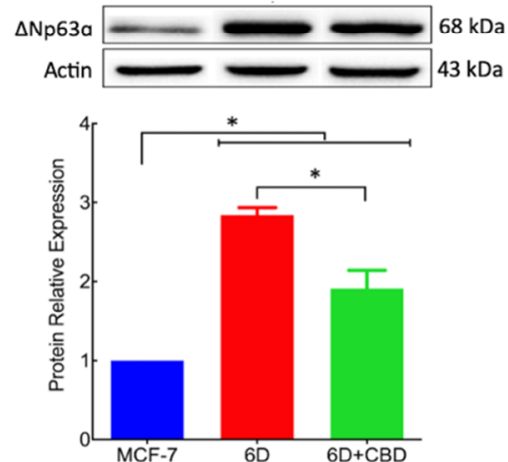

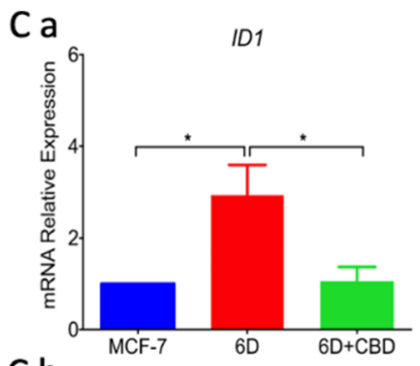

$\mathrm{Cb}$
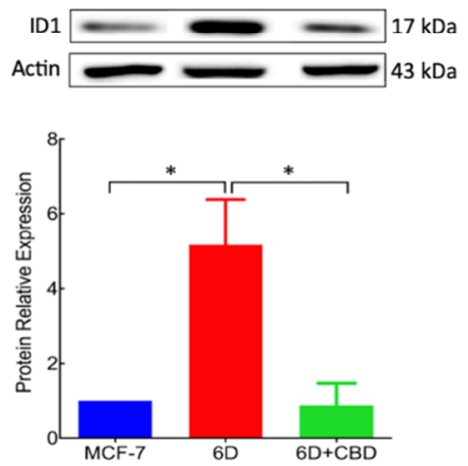

Figure 6. The CBD modified the overexpression of effector proteins downstream in the IL-1 $\beta$-induced pathway. (Aa) mRNA relative expression levels of gene BIRC3 that codifies for the BIRC3 protein was determined in MCF-7cells and 6D cells treated or not treated with CBD. The data of mRNA expression in all the cases were normalized to the expression of gene RPLP0. (Ab) Representative Western blot of BIRC3 in the three cell types mentioned above. Densitometric values corresponding to BIRC3 levels were normalized to actin and expressed relative to those in MCF-7 cells. (Ba) mRNA relative expression of the TP63 gene and the $\triangle \mathrm{NP} 63 \alpha$ isoform $(\mathbf{B b})$. (Ca) mRNA relative expression levels of gene ID1 and ID1 protein $(\mathbf{C b})$. Representative Western blot of ID1 levels in the cells. mRNA expression and Western blot results represent the average of three independent batches of cells (biological replicates, $n=3) \pm$ SD. Asterisks indicate $p<0.05$.

Additionally, gene ID1 expression was evaluated because of its association with cancer progression in several cell models [11]. We report here, for the first time, that ID1 overexpression is induced by IL-1 $\beta$ stimulation. Its mRNA expression was increased 3 fold in $6 \mathrm{D}$ cells and decreased by CBD 
treatment to MCF-7 cell levels (Figure $6 \mathrm{Ca}$ ). The same effect was shown at protein levels as 6D cells overexpressed BIRC3 8 fold, $\triangle \mathrm{NP} 63 \alpha 3$ fold, and ID1 5 fold. In 6D cells treated with CBD, BIRC3 and ID1 levels were reduced to the levels in MCF-7 cells and $\triangle \mathrm{NP} 63 \alpha$ was reduced $33 \%$ compared to levels in $6 \mathrm{D}$ cells (Figure $6 \mathrm{Ab}, \mathrm{Bb}, \mathrm{Cb}$ ).

These results demonstrated that the over-expression of genes and proteins that are effectors in IL-1 $\beta$-activated signaling pathways were downregulated by CBD.

\subsection{CBD Inactivated Akt and Blocked Cell Migration}

A crucial step in IL-1 $\beta$-induced signaling pathways, leading to EMT and other pathways involved in cancer progression, is the increased phosphorylation of AKT(ser 473), a component of the protein complex PI3K/AKT [5,18]. As it has been shown that cannabinoid treatment diminished AKT phosphorylation in different cancer models $[12,19,20]$, we investigated whether CBD decrease of total $\mathrm{AKT}$ as well as its activation could be related to the IL- $1 \beta$ EMT progression. Figure $7 \mathrm{~A}$ shows a representative Western blot of total AKT in MCF-7 and 6D cells treated or not treated with CBD. Total AKT levels were 3 fold higher in 6D than in MCF-7 cells. The CBD and wortmannin decreased the levels of total AKT to half of the levels found in 6D cells. Figure 7B shows the ratio of AKTSer473 over AKT ( $\mathrm{pAKT} / \mathrm{AKT}$ ). The addition of CBD to $6 \mathrm{D}$ cells caused a decrease of $80 \%$ in the $\mathrm{pAKT} / \mathrm{AKT}$ ratio and addition of wortmannin caused a 50\% decrease. To confirm that inactivation of AKT phosphorylation by these compounds could inhibit the high migration ability of 6D cells, a wound healing assay was performed. The microscope images of the migrating cells showed that even at long times, CBD and wortmannin-treated cells had a lower capacity to migrate and close the wound. At $72 \mathrm{~h}, 6 \mathrm{D}$ cells had closed $100 \%$ of the wounded area, while cells treated with CBD or wortmannin could not do so (Figure 7C).

A
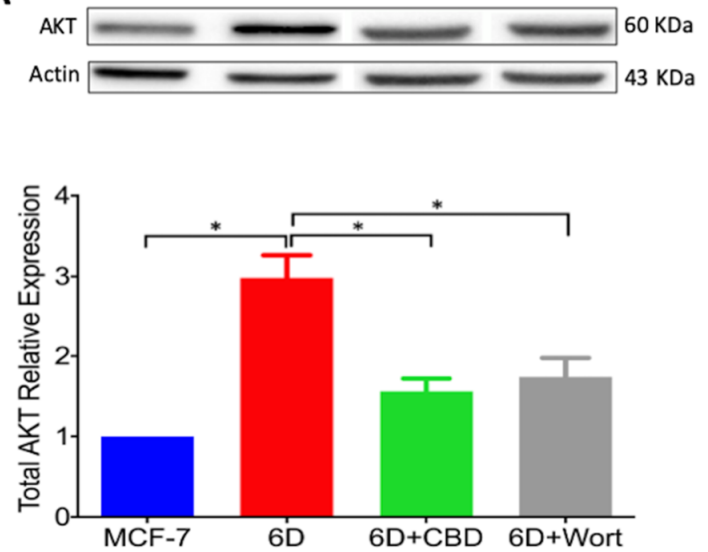

B
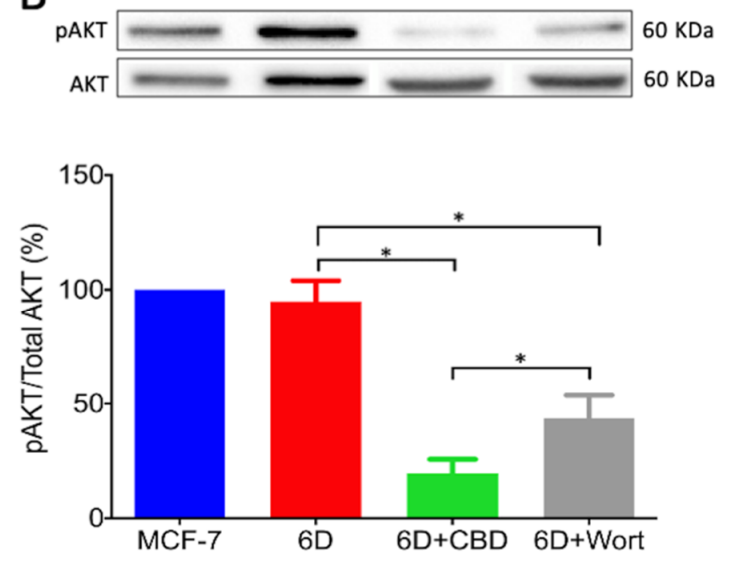

C

$72 \mathrm{~h}$
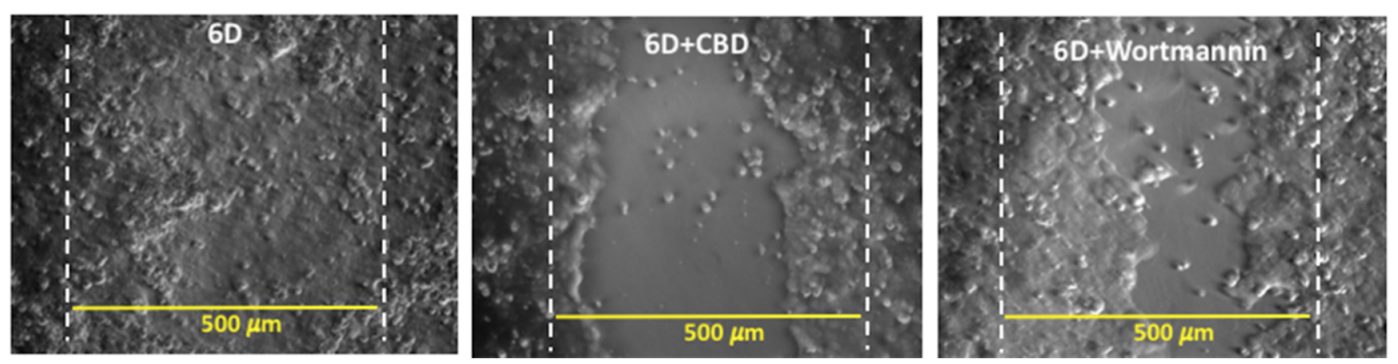

Figure 7. The CBD decreased the expression and activation of AKT, blocking cell migration. (A) Representative Western blot of AKT in MCF-7 and 6D treated or not treated with CBD and $6 \mathrm{D}$ cells treated with $100 \mu \mathrm{M}$ wortmannin. Densitometric values correspond to total AKT obtained from three independent experiments $(n=3) \pm \mathrm{SD}$. All values were normalized to actin and expressed 
relative to those in MCF7 cells. Asterisks indicate $p<0.05$. (B) Representative Western blot of pAKT(Ser473) in the conditions mentioned above. Percentage of AKT phosphorylation expressed as pAKT/AKT ratio. (C) To illustrate the effect of wortmannin inhibition of AKT phosphorylation in the cell migration, wound healing assays were performed with 6D, CBD-treated and wortmannin-treated cells. The percentage of the wound closure was calculated as done in Figure 2. Asterisks indicate $p<0.05$.

\section{Discussion}

In vitro and in vivo studies have shown that CBD functions differ in every type of cancer and depends on the expression of cannabinoid receptors linked to a variety of signaling pathways [13]. Aggressive breast cancer cell lines, such as MDA-MB-231, colon CaCo2 cells, and lung tissue A549, have been reported to have great sensitivity to CBD, while non-invasive cells are not affected [12,21]. The present work is focused on CBD blockage and reversion of cellular and molecular mechanisms induced by IL- $1 \beta$ that transformed non-invasive cells to an invasive phenotype. In the invasive $6 \mathrm{D}$ cells a significant increase of receptor CB1 expression was found, while it was expressed in low levels in the non-invasive control MCF-7 cells. This condition could explain the higher sensitivity of $6 \mathrm{D}$ cells to the treatment with CBD as shown in Figure 1. The specificity of binding of CBD to CB1, was determined using the agonist AM251. Previous treatment of 6D cells with the agonist and then CBD increased cell viability, indicating the dependency of viability on the levels of the receptor. Analysis of CB1mRNA expression showed that CBD had no effect on the transcription of gene CNR1 but greatly decreased the levels of the receptor, cell migration, and resistance to cisplatin. The negative regulation of $\mathrm{CB} 1$ levels by CBD could occur by internalization of the CB1/CBD complex and the recycling of $\mathrm{CB} 1$ to different cellular pathways. In the central nervous system, the CB1/CBD complex has been reported to be internalized and degraded and also that de novo synthesized receptor is directed to the cell surface [22,23]. The CBD-treated cells lost almost 50\% of their CB1 receptors and important features of malignancy; therefore, it would be expected to be less aggressive cells.

For migration to occur, loss of cell contacts and the disorganization of the actin cytoskeleton that maintain epithelial architecture have to take place. We found that CBD upregulated the levels of E-cadherin and $\beta$-catenin mRNAs, and the proteins reestablished their localization at the adherens junctions. These processes favored the recovery of cell contacts and the epithelial morphology therefore blocking cell migration.

Furthermore, we report here that $\mathrm{CBD}$ is an inhibitor of $\beta$-catenin nuclear translocation. We have previously shown that the endocannabinoid anandamide blocks $\beta$-catenin entry into the nucleus induced by IL- $1 \beta$ during the EMT. Degradation of cytoplasmic $\beta$-catenin inhibited the expression of malignancy-related genes [5]. In both cases, the two cannabinoids blocked the nuclear translocation. However, anandamide-induced degradation of cytoplasmic $\beta$-catenin, while CBD relocated $\beta$-catenin at the adherens junctions. In both cases the expression of malignant markers in $6 \mathrm{D}$ cells was greatly reduced $[5,16,17]$. In this work, we analyzed the expression of two genes, BIRC3 and TP63, the expression of which was increased by the activation of the IL-1 $\beta / \mathrm{IL}-1 \mathrm{R} / \beta$-catenin pathway. Over-expression of proteins BIRC3 and $\triangle \mathrm{Np} 63 \alpha$, two important effectors in the pathways that regulate resistance to doxorubicin and cisplatin, were significantly reduced by CBD. Downregulation of resistance to cisplatin by CBD explains the acquired sensitivity to drugs by $6 \mathrm{D}$ cells. All these activities of CBD support its role as an inhibitor of the IL- $1 \beta / \mathrm{IL}-1 \mathrm{R} / \beta$-catenin pathway and a possible inducer of mesenchymal reversion to an epithelial phenotype (drug-sensitive).

Additionally, we provide here the first evidence that the gene ID1 and the protein ID1 are overexpressed in $6 \mathrm{D}$ cells stimulated with IL-1 $\beta$. However, we cannot conclude that the protein expression occurs via the IL-1 $\beta / \mathrm{IL}-1 \mathrm{R} / \beta$-catenin pathway. ID1 protein has been reported in actively proliferating cells and has been identified in more than 20 tumorigenic cancer types [24]. Significant reduction by CBD of ID1 expression and other protein markers of malignancy supports our hypothesis that $\mathrm{CBD}$ has a role in the reversion of a malignant phenotype. It has been reported that overexpression 
of ID1 in advanced bladder tumor cells is associated with the expression of mesenchymal markers, and when downregulated by ID-1si-RNA, the cells expressed epithelial markers [25].

Activation of AKT is a crucial step in the IL-1 $\beta$-induced EMT which regulates downstream progression of the IL- $1 \beta / \mathrm{IL}-1 \mathrm{R} / \beta$-catenin pathway. The present results showed that $\mathrm{CBD}$, through downregulation of AKT phosphorylation, inhibited downstream activity of the IL-1 $\beta$ pathway and the expression of malignant markers such as migration and drug resistance. When wortmannin, a specific inhibitor of AKT phosphorylation, was added to the $6 \mathrm{D}$ cells, these showed reduced migration to levels similar to those in cells treated with CBD. It was very recently shown in an in silico study that CBD binds to the active site of PI3K and AKT [26]. As a consequence of AKT inactivation by CBD, a crucial point for crosstalk in the IL-1 $\beta$ - and CBD-induced pathways, $6 \mathrm{D}$ cells could undergo reversion to an epithelial phenotype.

The acidic precursor of CBD (cannabidiolic acid, CBDA) has been able to inhibit the migration of breast cancer cells and to downregulate the proto-oncogene c-fos and the cyclooxygenase-2 (COX-2), highlighting the possibility that CBDA might act on a common pathway of inflammation and cancer mechanisms [27]. Here, we demonstrated this association, for the first time, between CBD and the inflammatory IL-1 $\beta / \mathrm{IL}-1 \mathrm{R} / \beta$-catenin pathway through CB1 activation.

A diagrammatic model of our results and hypothesis about CBD induction of phenotype reversion is shown in Figure 8.

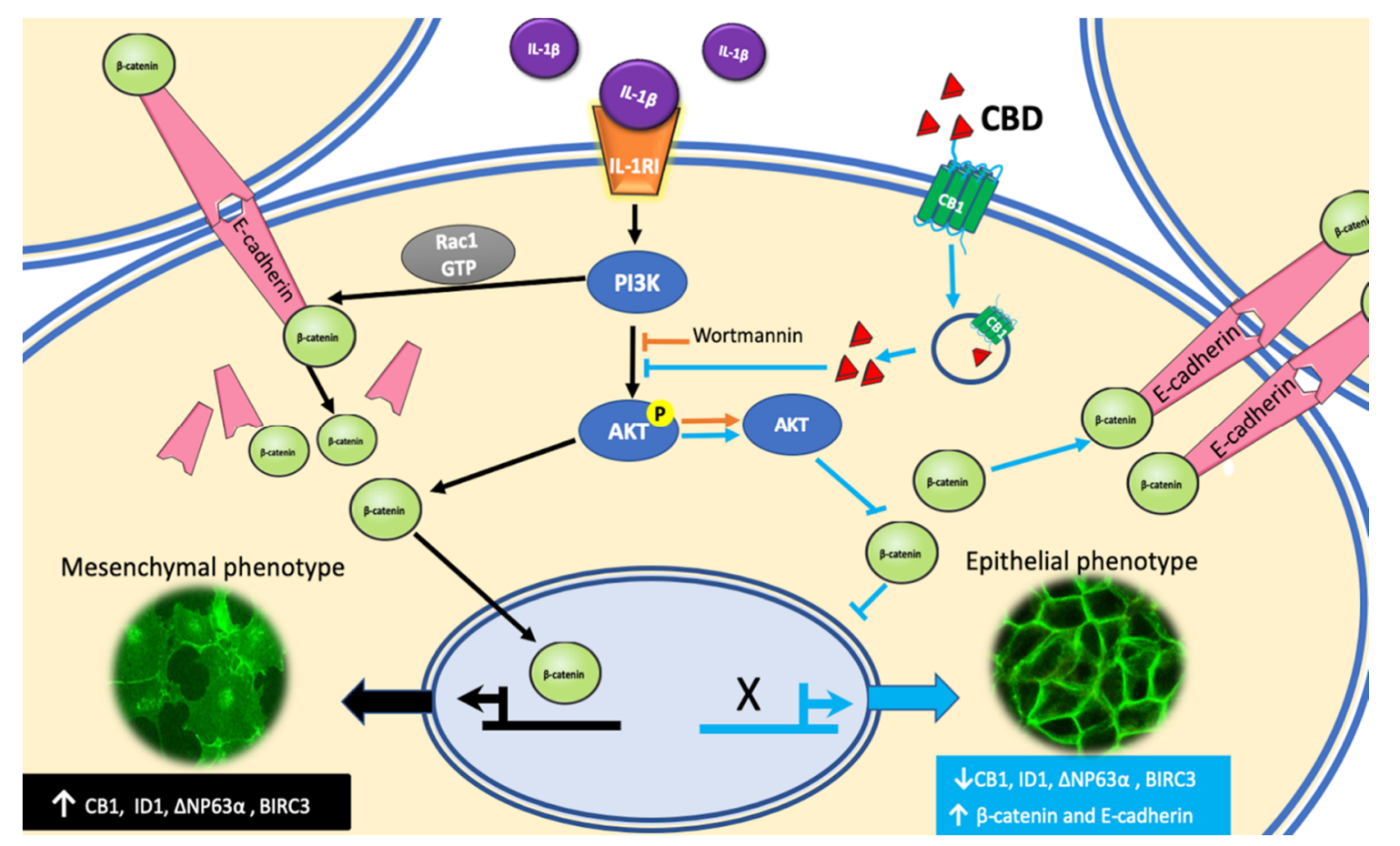

Figure 8. CBD blocks the IL-1 $\beta / \mathrm{IL}-1 \mathrm{RI} / \beta$-catenin pathway and induces an epithelial phenotype. A hypothetical model of CBD blockage of the IL-1 $\beta$-activated signaling pathway that leads into a malignant phenotype is represented by the black pathway. CBD binding to its receptor CB1 induces AKT activation and blocks the translocation of $\beta$-catenin into the nucleus. CBD also decreases the expression of malignant markers such as $\triangle \mathrm{NP} 63 \alpha$ isoform, BIRC3, and ID1 (blue pathway). CBD increased epithelial marker E-cadherin and its associated $\beta$-catenin in the adherens junction resulting in cells with an epithelial phenotype.

Cell reprogramming has been thought to depend mainly on a genetic program; however, over-expression of E-cadherin has been shown to replace the presence of the gene Oct4, thought to be a key participant in the process. A number of factors have been identified that inhibit or promote reprogramming through recognition of molecular programs involving PI3K/AKT 
and $\mathrm{Wnt} / \beta$-catenin [28]. We observed these processes in vitro when non-invasive MCF-7 breast cancer cells were treated with IL-1 $\beta$, inducing an EMT program that changed the cells into an aggressive mesenchymal phenotype. Our present data showed that CBD could be the inducer of a mesenchymal-epithelial transition that would revert 6D cells to a non-invasive phenotype. This ability of CBD may be very useful in cancer therapy, as malignant cells treated with CBD will become sensitive to conventional cancer therapy.

Supplementary Materials Figure S1 shows the preliminary results obtained with an in vivo model using female nu/nu mice. When $6 \mathrm{D}$ cells were injected subcutaneously into the right flank of the body, tumors of approximately $8 \mathrm{~mm}$ in diameter developed after 40 days. The CBD, injected at that time directly into the tumor, reduced the tumor size to $50 \%$ after 72 days. These data show that CBD has the potential to act as an anti-tumorigenic drug.

\section{Materials and Methods}

\subsection{Reagents}

The RH-Oil5 ${ }^{\mathrm{TM}}$ containing a concentration of $23.36 \mathrm{mg} / \mathrm{mL}$ of purified CBD was acquired from (HempMeds ${ }^{\mathrm{TM}}$, Monterrey, NL. México). A $1000 \mu \mathrm{M}$ stock solution was prepared by dilution in DMSO. Aliquots from this stock were taken to obtain CBD concentrations to make a dose-response curve. Coconut oil (do TERRA ${ }^{\mathrm{TM}}$ Pleasant Grove, UT, USA) $0.01 \%$ final concentration was used as the vehicle. Wortmannin (Sigma-Aldrich, St. Louis, MO, USA) was used at $250 \mathrm{nM}$ and cisplatin (CDDP, PISA ${ }^{\mathrm{TM}}$ Pharmaceutics, Guadalajara, Mexico) was used at $100 \mu \mathrm{M}$. Both compounds were used as previously reported in 6D cells [3,17]. The AM251 (Sigma-Aldrich, St Missouri, MO, USA) was used at $100 \mathrm{nM}$ as CB1 receptor antagonist.

\subsection{Primary Antibodies}

The human antibodies used were anti- $\Delta \mathrm{Np} 63 \alpha$, anti-CB1, anti-cIAP2/BIRC3, and anti-ID1 (GeneTex, Irvine, CA, USA). Anti-AKT and anti-Phospho-AKT-Ser473 (Cell Signaling Technology, Danvers, MA, USA); anti-E-cadherin (BD; Baltimore, MD, USA); anti- $\beta$-catenin (Thermo Scientific, Waltham, MA, USA).

\subsection{Cell Culture}

The MCF-7 cells were obtained from (ATCC, Manasas, VA, USA). The 6D cells, a clone selected from MCF-7 non-invasive cells that was highly responsive to IL-1 $\beta$ stimulus and transformation to malignancy by the IL-1 $\beta$-induced EMT [4,5], were used as the cellular model. All the cells were cultured in DMEM-F12 medium supplemented with $10 \%$ fetal bovine serum (FBS), penicillin (5000 U/mL), and streptomycin $(5000 \mu \mathrm{g} / \mathrm{mL}$ ) from Gibco BRL (Grand Island, NY, USA). Cultures were incubated at $37^{\circ} \mathrm{C}$ with $5 \% \mathrm{CO}_{2}$. Before performing the experiments with $\mathrm{CBD}$, the $6 \mathrm{D}$ cells were incubated with $20 \mathrm{ng} / \mathrm{mL}$ of human recombinant IL-1 $\beta$ for $48 \mathrm{~h}$ (to amplify their response to IL-1 $\beta$ stimulus) and then rinsed and cultured with regular medium (Peprotech, Rocky Hill, NJ, USA).

\subsection{Cell Viability Assays in the Presence of CBD}

The MCF7 and 6D cells $\left(2 \times 10^{4}\right.$ cells/well) cultured in 96 well plates for $48 \mathrm{~h}$, as indicated above, were switched to culture medium only supplemented with $1 \%$ FBS for $18 \mathrm{~h}$ and then divided in two groups: (1) cells treated with CBD at final concentrations of 5, 10, 15, and $20 \mu \mathrm{M}$; and (2) cells treated with coconut oil (vehicle) at a final concentration of $0.01 \%$. After $48 \mathrm{~h}, 10 \mu \mathrm{L}$ of WST-1 solution were added to each well (Roche Applied Science, Mannheim, Germany) and after $2 \mathrm{~h}$ the optical density, resulting from the reduction of tetrazolium salt in the solution by the viable cells, was measured at $450 \mathrm{~nm}$ in a microplate reader (Sunrise ${ }^{\mathrm{TM}}$, Tecan, Switzerland). The viability of MCF-7 cells, used as control of non-invasiveness, and that of $6 \mathrm{D}$ cells cultured in medium with only $1 \%$ FBS in the absence 
of CBD were given $100 \%$ values. To analyze viability data, three independent experiments were carried out (biological replicates) and each one was performed in triplicate (assay replication, $n=9$ ).

\subsection{CB1 Receptor Antagonist}

The specific antagonist of the CB1 receptor AM251 was utilized at a final concentration of $100 \mathrm{nM}$ [9]. The AM251 was added to the cell cultures prior to addition of CBD, and then the cells were cultured for $48 \mathrm{~h}$ as indicated above.

\subsection{Resistance to Cisplatin}

Fifty thousand cells (MCF-7 or 6D) per well were seeded in 96 well culture plates and incubated for $24 \mathrm{~h}$, then switched to medium with only $1 \%$ of FBS for $18 \mathrm{~h}$. After this, cells were treated with different conditions: (1) cells with $100 \mu \mathrm{M}$ cisplatin; (2) cells with $10 \mu \mathrm{M}$ CBD; (3) cells with $10 \mu \mathrm{M}$ CBD and $100 \mu \mathrm{M}$ cisplatin; (4) cells only incubated in 1\% FBS culture medium. All the cells were incubated for $48 \mathrm{~h}$ at $37^{\circ} \mathrm{C}$. To quantify cell viability for each condition the WST-1 assay, described above, was utilized.

\subsection{Wound Healing Assay}

The migrating ability of the cells was determined by the wound healing assay adapted from Shi and collaborators [29]. Parental MCF-7 and 6D cells were grown in 24 well dishes to reach 90\% confluence in normal culture medium. Then medium was changed to contain only $1 \%$ FBS and cells cultured for $18 \mathrm{~h}$. The monolayers were wounded in a confluent zone by scratching the cells with a sterilized $10 \mu \mathrm{L}$ pipette tip to obtain a clear area of $500 \mu \mathrm{m}$ width. The wounded monolayers were washed with $1 \times$ PBS to eliminate debris and incubated in $1 \%$ FBS culture medium in the presence or absence of $20 \mathrm{ng} / \mathrm{mL}$ IL-1 $\beta, 10 \mu \mathrm{M}$ CBD or $250 \mu \mathrm{M}$ wortmannin for $1 \mathrm{~h}$. After this time, cell migration was registered at $0,24,48$, and $72 \mathrm{~h}$ using a phase-contrast objective in an Olympus inverted microscope. Cells protruding from the wound borders and those that had migrated into the wounded area were evaluated quantitatively by image analysis, using the Image-Pro Plus software. Measurements were carried out in three independent experiments (biological replicates) and each one was performed in quadruplicate (assay replication, $n=12$ ).

\subsection{Gene Expression and Quantitative Real-Time PCR ( $q R T-P C R)$}

Total RNA was extracted from the cells using Trizol ${ }^{\mathrm{TM}}$ reagent (Invitrogen, Carlsbad, CA, USA) following the manufacturer's recommendations. Integrity of total RNA components was assessed by electrophoresis in $2 \%$ agarose gels. The nucleic acid yield, quantification and purity (ratio 260/280nm) were analyzed using Nanodrop 2000, Microvolume UV-visible spectrophotometer (Thermo- Scientific, Wilmington, DE, USA). Samples were stored at $-20^{\circ} \mathrm{C}$.

The cDNA synthesis was performed according to the High Capacity cDNA Reverse Transcription protocol (Applied Biosystems, CA USA) using $500 \mathrm{ng}$ of total RNA. Reactions contained $2 \mu \mathrm{L}$ of 10× RT Buffer, $0.8 \mu \mathrm{L}$ of $25 \times$ dNTPs mix $(100 \mathrm{mM}), 2 \mu \mathrm{L} 10 \times$ random primer set, $50 \mathrm{U}$ Multi-Scribe Reverse Transcriptase, and nuclease-free water to make a volume of $10 \mu \mathrm{L}$. Table S1 shows the primer sequences of the selected genes $[5,30]$ and qRT-PCR conditions. Each primer pairs for the target gene were designed based on the sequence data obtained from GenBank. Real-time PCR was performed using Luminaris color HiGreen qPCR master mix (Thermo Fisher Scientific) in the Step One Real-Time PCR system (Thermo Fisher Scientific) according to the manufacturer's protocol. qPCRs contained $0.3 \mu \mathrm{M}$ of each RT-PCR primers pair, $5 \mu \mathrm{L}$ of $2 \times$ Master mix, $1 \mu \mathrm{g}$ cDNA and nuclease-free water to a final volume of $10 \mu \mathrm{L}$. Thermal cycling conditions were as following 1 cycle at $50^{\circ} \mathrm{C}$ for $2 \mathrm{~min}, 1$ cycle at $95^{\circ} \mathrm{C}$ for $10 \mathrm{~min}, 40$ cycles at $95^{\circ} \mathrm{C}$ for $15 \mathrm{~s}, 60^{\circ} \mathrm{C}$ for $30 \mathrm{~s}$, and $72{ }^{\circ} \mathrm{C}$ for $30 \mathrm{~s}$. Three cDNA samples from each condition were analyzed. Data were normalized with the RPLPO housekeeping gene. Quantification of gene expression and relative expression were calculated with Analysis of quantitative RT-qPCR 
data $(\Delta \mathrm{Rn})$ using the LinRegPCR (ver. 11.0, Academic Medical Centre, University of Amsterdam, Amsterdam, The Netherlands) software.

\subsection{SDS-PAGE and Western Blotting}

Protein extracts were obtained from cell lysates using $1 \times$ RIPA buffer supplemented with Complete $^{\mathrm{TM}}$ Protease Inhibitor Cocktail (Roche Applied Science, Mannheim, Germany). Protein concentrations were determined by the BCA method (Pierce ${ }^{\mathrm{TM}} \mathrm{BCA}$ Protein Assay Kit). Thirty micrograms of protein were loaded per lane and separated by SDS-PAGE in $10 \%$ polyacrylamide gels, blotted onto nitrocellulose membranes and blocked with non-fat milk. The membranes were exposed to the anti-human antibodies listed in the Materials Section. The anti-actin monoclonal antibody, kindly donated by JM Hernández (CINVESTAV-IPN), was utilized to detect actin. The HRP-tagged secondary antibodies were anti-rabbit or anti-mouse (1:5000) (Jackson Immunoresearch, West Grove, PA, USA). Chemiluminescent detection was done with Immobilon $^{\mathrm{TM}}$ and recorded on a ChemiDoc imaging device (Bio-Rad Laboratories, Hercules, CA, USA) for densitometric analyses with ImageLab ${ }^{\mathrm{TM}}$ software (v 6.0, Bio-Rad Laboratories, CA, USA). All proteins were identified by Western blot from three independent experiments (biological replicates, $n=3$ ).

\subsection{Immunofluorescence}

For immuno-localization MCF-7 and 6D cells were grown on glass coverslips and fixed with $3.7 \%$ formaldehyde for $20 \mathrm{~min}$ and permeabilized with $0.1 \%$ Triton X-100 in PBS $1 \times$ for $5 \mathrm{~min}$ at RT. Cells were treated with PBS containing 0.1\% Tween 20, 2\% BSA, and rinsed with PBS before being exposed for $1 \mathrm{~h}$ at $37^{\circ} \mathrm{C}$ to the different primary antibodies: $\beta$-Catenin (1:100 dilution) and E-Cadherin (1:100 dilution). Cells were then incubated with anti-mouse IgG or anti-Rabbit IgG conjugated with Alexa 488 at 1:100 dilution for $1 \mathrm{~h}$ at RT. Visualization of actin was performed staining with TRITC-phalloidin for $20 \mathrm{~min}$ at RT. Nuclei were stained with a $0.1 \%$ 4',6-diamidino-2-phenylindole (DAPI) in a PBS/Triton solution for 5 min. Coverslips were mounted with VectaShield H-1000. Cells were observed in an Olympus 50x epifluorescence inverted microscope. All proteins were identified by immunofluorescence from three independent experiments (biological replicates, $n=3$ ). Images acquired with a digital camera Olympus DP72 were analyzed with Image-pro Plus software (v. 3.0., Media Cybernetics, Rockville, MD, USA).

\subsection{1. $\beta$-catenin Quantification by Image Analysis}

Cell images captured for immuno-localization were utilized to quantify the amount of $\beta$-catenin in specific cell compartments (intercellular junctions and nuclei) using fluorescence density analysis. Before starting the analysis, the captured images were subjected to a deconvolution process to eliminate background noise (Deconvolution Image J software, Rasband, W.S., U. S. National Institutes of Health, Bethesda, MD, USA). Subsequently, 150 cells in six randomly chosen fields were selected to quantify the relative levels of the $\beta$-catenin signal associated with the intercellular junctions using a surface plot tool. The obtained data were used for statistical analysis. To measure the nuclear $\beta$-catenin, cells were stained with Alexa 488 and counterstained with TRITC-Phalloidin to set cell limits and visualize actin organization and DAPI to identify the nuclei. Considering the size and roundness of the nuclei (marked by a dotted circle) IF quantification of these areas was performed. One hundred and fifty cells were examined from three independent experiments. IF data were used for statistical determinations. The captured images of cells were processed in Image-Pro Plus Ver. 7.0, and Image J software.

\subsection{Statistical Analysis}

Data are presented as mean $\pm \mathrm{SD}$. In all cases, they represent at least three independent determinations (biological replicates) each done in triplicate. The v 6.0 of GraphPad Software (La Jolla CA, USA) was used for statistical analysis. Multiple comparisons were done using 2-way ANOVA and the Dunnett's multiple comparisons test. $p$-Values $\leq 0.05$ were considered significant. 


\section{Conclusions}

We reported for the first time that CBD reverts the epithelial-mesenchymal transition induced by the inflammatory cytokine IL-1 $\beta$, reprogramming invasive $6 \mathrm{D}$ cells to become cells with an epithelial phenotype.

Supplementary Materials: Supplementary materials can be found at http://www.mdpi.com/1422-0067/21/7/2429/s1.

Author Contributions: Conceptualization, I.M. and A.M.C.; methodology, L.G.-M., H.Z.-M. and M.d.C.D.-R.; validation, A.M.C. and I.M.; formal analysis, L.G.-M. and H.Z.-M.; investigation, L.G.-M., H.Z.-M. and A.M.C.; resources, I.M. and J.T.R.; writing—original draft preparation; L.G.-M., and H.Z.-M.; writing—review and editing, I.M. and A.M.C.; supervision, I.M.; project administration, I.M.; funding acquisition, J.T.R. and I.M. All authors have read and agreed to the published version of the manuscript.

Funding: This work was partially supported by Project 224 from Fondo de Investigación Cientifica y Desarrollo Tecnológico del CINVESTAV.

Acknowledgments: We are grateful to Ian C. West and Michael Schnoor for their comments on the writing of this manuscript and to Alejandro Trejo for technical support.

Conflicts of Interest: The authors declare no conflict of interest.

\section{Abbreviations}

$\begin{array}{ll}\text { CBD } & \text { Cannabidiol } \\ \triangle \text { NP63 } \alpha & \text { Alpha Isoform of Tumor Protein 63 } \\ \text { EMT } & \text { Epithelial-Mesenchymal Transition } \\ \text { MET } & \text { Mesenchymal-Epithelial Transition }\end{array}$

\section{References}

1. Yang, L.; Lin, P.C. Mechanisms that drive inflammatory tumor microenvironment, tumor heterogeneity, and metastatic progression. Semin. Cancer Biol. 2017, 47, 185-195. [CrossRef] [PubMed]

2. Apte, R.N.; Dotan, S.; Elkabets, M.; White, M.R.; Reich, E.; Carmi, Y.; Song, X.; Dvozkin, T.; Krelin, Y.; Voronov, E. The involvement of IL-1 in tumorigenesis, tumor invasiveness, metastasis and tumor-host interactions. Cancer Metastasis Rev. 2006, 25, 387-408. [CrossRef] [PubMed]

3. Franco-Barraza, J.; Valdivia-Silva, J.E.; Zamudio-Meza, H.; Castillo, A.; García-Zepeda, E.A.; Benítez-Bribiesca, L.; Meza, I. Actin Cytoskeleton Participation in the Onset of IL-1 $\beta$ Induction of an Invasive Mesenchymal-like Phenotype in Epithelial MCF-7 Cells. Arch. Med. Res. 2010, 41, 170-181. [CrossRef] [PubMed]

4. Perez-Yepez, E.A.; Ayala-Sumuano, J.-T.; Reveles-Espinoza, A.M.; Meza, I. Selection of a MCF-7 Breast Cancer Cell Subpopulation with High Sensitivity to IL-1 $\beta$ : Characterization of and Correlation between Morphological and Molecular Changes Leading to Increased Invasiveness. Int. J. Breast Cancer 2012, 2012, 1-12. [CrossRef]

5. Perez-Yepez, E.A.; Ayala-Sumuano, J.-T.; Lezama, R.; Meza, I. A novel $\beta$-catenin signaling pathway activated by IL-1 $\beta$ leads to the onset of epithelial-mesenchymal transition in breast cancer cells. Cancer Lett. 2014, 354, 164-171. [CrossRef]

6. Lim, B.; Woodward, W.A.; Wang, X.; Reuben, J.M.; Ueno, N.T. Inflammatory breast cancer biology: The tumour microenvironment is key. Nat. Rev. Cancer 2018, 18, 485-499. [CrossRef]

7. Kalluri, R.; Weinberg, R.A. The basics of epithelial-mesenchymal transition. J. Clin. Invest. 2009, 119, 1420-1428. [CrossRef]

8. Mouhamed, Y.; Vishnyakov, A.; Qorri, B.; Sambi, M.; Frank, S.S.; Nowierski, C.; Lamba, A.; Bhatti, U.; Szewczuk, M.R. Therapeutic potential of medicinal marijuana: An educational primer for health care professionals. Drug. Healthc. Patient Saf. 2018, 10, 45-66. [CrossRef]

9. Preet, A.; Qamri, Z.; Nasser, M.W.; Prasad, A.; Shilo, K.; Zou, X.; Groopman, J.E.; Ganju, R.K. Cannabinoid Receptors, CB1 and CB2, as Novel Targets for Inhibition of Non-Small Cell Lung Cancer Growth and Metastasis. Cancer Prev. Res. 2011, 4, 65-75. [CrossRef]

10. Massi, P.; Solinas, M.; Cinquina, V.; Parolaro, D. Cannabidiol as potential anticancer drug. Br. J. Clin. Pharmacol. 2013, 75, 303-312. [CrossRef] 
11. McAllister, S.D.; Christian, R.T.; Horowitz, M.P.; Garcia, A.; Desprez, P.-Y. Cannabidiol as a novel inhibitor of Id-1 gene expression in aggressive breast cancer cells. Mol. Cancer Ther. 2007, 6, 2921-2927. [CrossRef] [PubMed]

12. Shrivastava, A.; Kuzontkoski, P.M.; Groopman, J.E.; Prasad, A. Cannabidiol Induces Programmed Cell Death in Breast Cancer Cells by Coordinating the Cross-talk between Apoptosis and Autophagy. Mol. Cancer Ther. 2011, 10, 1161-1172. [CrossRef] [PubMed]

13. Alexander, A.; Smith, P.F.; Rosengren, R.J. Cannabinoids in the treatment of cancer. Cancer Lett. 2009, 285, 6-12. [CrossRef] [PubMed]

14. Meng, W.; Takeichi, M. Adherens Junction: Molecular Architecture and Regulation. Cold Spring Harb. Perspect. Biol. 2009, 1, a002899. [CrossRef] [PubMed]

15. Castillo, A.; Ortuño-Pineda, C.; Flores-Maldonado, C.; Larre, I.; Rendón, J.M.; Hinojosa, L.; Ponce, A.; Ogazón, A.; Serrano, M.; Valdes, J.; et al. Ouabain modulates the adherens junction in renal epithelial cells. Cell. Physiol. Biochem. 2019, 52, 1381-1397. [CrossRef]

16. Mendoza-Rodríguez, M.; Arévalo Romero, H.; Fuentes-Pananá, E.M.; Ayala-Sumuano, J.-T.; Meza, I. IL-1 $\beta$ induces up-regulation of BIRC3, a gene involved in chemoresistance to doxorubicin in breast cancer cells. Cancer Lett. 2017, 390, 39-44. [CrossRef]

17. Mendoza-Rodríguez, M.; Ayala-Sumuano, J.; García-Morales, L.; Zamudio-Meza, H.; Pérez-Yepez, E.; Meza, I. IL-1 $\beta$ Inflammatory Cytokine-Induced TP63 Isoform $\triangle$ NP63 $\alpha$ Signaling Cascade Contributes to Cisplatin Resistance in Human Breast Cancer Cells. Int. J. Mol. Sci. 2019, 20, 270. [CrossRef]

18. Liu, P.; Cheng, H.; Roberts, T.M.; Zhao, J.J. Targeting the phosphoinositide 3-kinase pathway in cancer. Nat. Rev. Drug Discov. 2009, 8, 627-644. [CrossRef]

19. Ozaita, A.; Puighermanal, E.; Maldonado, R. Regulation of PI3K/Akt/GSK-3 pathway by cannabinoids in the brain. J. Neurochem. 2007, 102, 1105-1114. [CrossRef]

20. Caffarel, M.M.; Andradas, C.; Mira, E.; Pérez-Gómez, E.; Cerutti, C.; Moreno-Bueno, G.; Flores, J.M.; García-Real, I.; Palacios, J.; Mañes, S.; et al. Cannabinoids reduce ErbB2-driven breast cancer progression through Akt inhibition. Mol. Cancer 2010, 9, 196. [CrossRef]

21. ChoiPark, W.-H.-D.; Baek, S.-H.; Chu, J.-P.; Kang, M.-H.; Mi, Y.-J. Cannabidiol Induces Cytotoxicity and Cell Death via Apoptotic Pathway in Cancer Cell Lines. Biomol. Ther. 2008, 16, 87-94. [CrossRef]

22. Gyombolai, P.; Boros, E.; Hunyady, L.; Turu, G. Differential $\beta$-arrestin 2 requirements for constitutive and agonist-induced internalization of the CB1 cannabinoid receptor. Mol. Cell. Endocrinol. 2013, 372, 116-127. [CrossRef] [PubMed]

23. Nogueras-Ortiz, C.; Yudowski, G.A. The Multiple Waves of Cannabinoid 1 Receptor Signaling. Mol. Pharmacol. 2016, 90, 620-626. [CrossRef] [PubMed]

24. Ling, M.-T.; Wang, X.; Zhang, X.; Wong, Y.-C. The multiple roles of Id-1 in cancer progression. Differentiation 2006, 74, 481-487. [CrossRef]

25. Hu, H.; Wang, Y.L.; Wang, G.W.; Wong, Y.C.; Wang, X.F.; Wang, Y.; Xu, K.X. A novel role of Id-1 in regulation of epithelial-to-mesenchymal transition in bladder cancer. Urol. Oncol. Semin. Orig. Investig. 2013, 31, 1242-1253. [CrossRef]

26. Mittal, R.; Chaudhry, N.; Mukherjee, T.K. Targeting breast cancer cell signaling molecules PI3K and Akt by phytochemicals Cannabidiol, Nimbin and Acetogenin: An in silico approach. J. Biomed. 2018, 3, 60-63. [CrossRef]

27. Pellati, F.; Borgonetti, V.; Brighenti, V.; Biagi, M.; Benvenuti, S.; Corsi, L. Cannabis sativa L. and Nonpsychoactive Cannabinoids: Their Chemistry and Role against Oxidative Stress, Inflammation, and Cancer. Biomed Res. Int. 2018, 2018, 1-15. [CrossRef]

28. Bizzarri, M.; Cucina, A.; Proietti, S. Tumor Reversion: Mesenchymal-Epithelial Transition as a Critical Step in Managing the Tumor-Microenvironment Cross-Talk. Curr. Pharm. Des. 2017, 23, 1-11. [CrossRef] 
29. Shi, H.; Wang, J.; Dong, F.; Wang, X.; Li, H.; Hou, Y. The effect of proteoglycans inhibited by RNA interference on metastatic characters of human salivary adenoid cystic carcinoma. BMC Cancer 2009, 9, 456. [CrossRef]

30. Wang, X.; Seed, B. A PCR primer bank for quantitative gene expression analysis. Nucleic Acids Res. 2003, 31, e154. [CrossRef]

(C) 2020 by the authors. Licensee MDPI, Basel, Switzerland. This article is an open access article distributed under the terms and conditions of the Creative Commons Attribution (CC BY) license (http://creativecommons.org/licenses/by/4.0/). 